\title{
Product Innovation With Partial Capacity Rollover
}

\author{
H. Dawid \\ M. Kopel \\ P.M. Kort
}




\title{
Product Innovation With Partial Capacity Rollover *
}

\author{
Herbert Dawid ${ }^{\dagger} \quad$ Michael Kopel $^{\ddagger} \quad$ Peter M. Kort ${ }^{\S}$
}

January 2019

\begin{abstract}
This paper analyzes how the transferability of production capacities from an established to a new product influences the incentives of a firm to invest in R\&D. A dynamic duopoly model is considered, where initially both firms offer a homogeneous product. The firms invest in production capacities and simultaneously in R\&D which determines their innovation rate. The firm that innovates first extends its product line and obtains a patent for the new product that prevents the other firm from catching up. Upon the launch of the new product, the innovator then has the option to transfer part of the capacity for the established product to the production process of the new product. If capacities can be rolled over to the new product, a trade-off can be detected in that this rollover option gives the larger firm more incentive to innovate, whereas the cannibalization effect gives the smaller firm a higher innovation incentive. As a logical consequence we find that the larger firm is expected to innovate first when the capacity transfer does not involve a too high capacity loss. However, if the losses of capacity transfer are considerable, the cannibalization effect starts to dominate and the smaller firm's incentive to innovate is larger.
\end{abstract}

Keywords: dynamic duopoly, product innovation, capital accumulation, differential games, Markov perfect equilibrium, capacity rollover

\section{Introduction}

This paper paper analyzes the product innovation incentives of an incumbent firm under dynamic competition. When an incumbent introduces a new product on the market, it essentially has a choice between single and dual rollover (Liang et al. (2014)). Single rollover means that, when a new product is introduced, the established (or old) product is phased out from the market. With dual rollover, the old product remains in the market along with the new product.

We consider a duopoly model with two incumbents. Initially this market is homogenous. Both firms hold production capacity which they can adjust by (dis)investing. In addition, both firms have an option to carry out a product innovation. To do so, they have to invest in R\&D. The larger the investment, the greater the breakthrough probability of

\footnotetext{
*The authors gratefully acknowledge financial support from the German Research Foundation (DFG) through the Collaborative Research Centre 1283 "Taming uncertainty and profiting from randomness and low regularity in analysis, stochastics and their application".

${ }^{\dagger}$ Department of Business Administration and Economics and Center for Mathematical Economics, Bielefeld University, email: hdawid@wiwi.uni-bielefeld.de.

${ }^{\ddagger}$ Department of Organization and Economics of Institutions, University of Graz, Austria, email: michael.kopel@uni-graz.at.

${ }^{\S}$ Department of Econometrics and Operations Research \& CentER, Tilburg University, The Netherlands and Department of Economics, University of Antwerp, Belgium, email: Kort@uvt.nl.
} 
achieving the innovation. We suppose that, once one firm innovates, it holds a patent that prevents the other firm from catching up in the innovation process. In other words, once the competitor innovates, the innovation option of the focal firm expires.

At the moment of innovation, the firm that innovates can determine its rollover strategy. More precisely, it can choose how much of the established production capacity it wants to roll over to the production process of the new innovative product. Transferring the full amount corresponds to the single rollover strategy.

After the time of innovation at which the innovator has decided about the capacity transfer, a heterogenous product market arises. Besides investing in the capacity for the established product, the innovator is able to further build up the capacity for the new product by undertaking the corresponding investments. The other firm just produces the established product and can (dis)invest to extend or reduce the corresponding capacity.

Studying this setting builds on earlier work on strategic capital accumulation (Reynolds (1987), Fershtman and Muller (1991), Dockner and Wagener (2014), see also the recent survey by Colombo and Labrecciosa (2017)). A seminal paper in this respect is Dockner (1992), in which the framework is a duopoly model where the firms operate on a homogenous product market. A main result of this paper is that firms invest more in a Markov-perfect equilibrium compared to open-loop Nash. Our paper also applies the Markov-perfect equilibrium approach and we also start out from a homogenous product market in duopoly where in addition both firms have the option to innovate. Another capital accumulation approach to innovation, but then in an optimal control setting, is Dockner et al. (2006). One of the main research questions treated in that paper is how much venture capital should be acquired to help finance the development of the firm in the innovation process.

We apply the multi-mode approach of differential games to capture the discrete change in the product market at the moment the new product is launched. These types of games are described in Dockner et al. (2000) under the heading piecewise deterministic games. The multi-mode approach used to capture changing product markets caused by product innovation breakthroughs, is also applied by Dawid et al. (2010, 2013, 2017b)). The present paper extends these works by giving the innovator the possibility to transfer production capacity from the established product to the new product.

In our previous work (Dawid et al. $(2010,2013,2017 \mathrm{~b})$ ) we have found that R\&D investments of the firm that is weaker on the established market are always larger. The point is that the cannibalization effect of the larger firm is stronger, which gives the larger firm less incentive to innovate. The present paper shows that, when giving the innovator the option to (partially) transfer the capacity of the old product to the new product, this result is changed provided that the firm does not loose too much of the capacity when transferring it to the production process of the new product. The reason is that, since the larger firm is able to transfer a large production capacity to the new product, it can make a head-start on the new product market and earn high revenues. This enlarges the value of the option to innovate for the large firm, which stimulates R\&D investments. We also show that, before the product innovation has been realized, the option to transfer capacity gives the firm an additional incentive to invest in the established product market capacity. The possibility of capacity rollover stimulates growth, because the firm anticipates the capacity transfer from the old to the new product associated with launching the new product when the product innovation is realized.

The paper is organized as follows. Section 2 presents the model, while Section 3 develops the different modes of the game. Section 4 presents the economic results and Section 5 concludes. 


\section{The Model}

We consider the (continuous-time) interaction of two firms producing a homogenous established product based on an old technology. At each point in time, each firm has an installed production capacity $K_{f o}(t), f=1,2$ for the old product and, assuming firms always fully utilize their capacities in production, the inverse demand function for the established product is given by

$$
p_{o}(t)=\alpha_{o}-\left(K_{1 o}(t)+K_{2 o}(t)\right),
$$

Firms can adjust their capacities according to

$$
\dot{K}_{f o}=I_{f o}-\delta_{o} K_{f o}, f=1,2
$$

with $I_{f o} \in \mathbb{R}$ and $\delta_{o}$ as depreciation rate. Investment costs are $C_{o}\left(I_{f o}\right)=\frac{c_{o}}{2} I_{f o}^{2}$.

At the same time, both firms engage in R\&D investments $I_{f r} \geq 0, f=1,2$, in order to develop a new vertically and horizontally differentiated product. For simplicity, it is assumed that the firm which develops the new product first, will be able to prevent the competing firm from entering the (sub)market for the new product due to patent protection or other technological reasons. The hazard rate of firm $f$ is given by

$$
h\left(I_{f r}\right)=\gamma I_{f r}, \gamma>0,
$$

where the R\&D investment costs are given by $C_{r}\left(I_{f r}\right)=\frac{c_{r}}{2} I_{f r}^{2}$.

Once one of the firms has reached the innovation breakthrough, it is able to offer a new product, which is horizontally differentiated from the old product and has a reservation price $\alpha_{n}>\alpha_{o}$. The inverse demand system now reads

$$
\begin{aligned}
& p_{o}=\alpha_{o}-\left(K_{1 o}+K_{2 o}\right)-\eta K_{f n} \\
& p_{n}=\alpha_{n}-\eta\left(K_{1 o}+K_{2 o}\right)-K_{f n},
\end{aligned}
$$

where it is assumed that firm $f \in\{1,2\}$ is the innovator, $K_{f n}$ denotes the production capacity for the new product and $\eta \in(-1,1)$ is the horizontal differentiation parameter. For positive (negative) values of $\eta$ the established and the new product are substitutes (complements).

At the point in time $\tau$ when the innovator introduces the new product, it reorganizes its production process and can transfer parts of its capacity for the established product to the production of the new product. Formally, the innovator $f$ chooses an amount $K_{f, \text { on }} \in\left[0, K_{f o}(\tau)\right]$ of capacity for the old product, which is rolled over to the production of the new product. We assume that a share $\kappa$, where $\kappa \in[0,1]$, of a unit of capacity for the established product can be productively used for producing the new product. It follows that the capacity for the new product at time $\tau$ is given by

$$
K_{f n}(\tau)=\kappa K_{f, o n}, \kappa \in[0,1] .
$$

The capacity transfer process exchanges part of the established product capacity for the innovative product capacity and in this process the established production capacity is reduced, i.e.

$$
K_{f o}\left(\tau^{+}\right)=K_{f o}^{-}\left(\tau^{-}\right)-K_{f, o n}
$$

where $K_{f o}\left(\tau^{+}\right)\left(K_{f o}^{-}\left(\tau^{-}\right)\right)$is the established product capacity right after (before) an amount $K_{f, o n}$ is transferred to the capacity of the new product. 
Furthermore, costs of $C_{o n}\left(K_{f, o n}\right)=c_{o n} K_{f, \text { on }}$ result from the rollover of the production capacity to the new product. After the introduction of the new product, its capacity can be adjusted in an analogous way to the capacity of the established product, i.e.

$$
\dot{K}_{f n}=I_{f n}-\delta_{n} K_{f n},
$$

with $I_{f n} \in \mathbb{R}$, depreciation rate $\delta_{n}$, and investment costs $C_{n}\left(I_{f n}\right)=\frac{c_{n}}{2} I_{f n}^{2}$.

We model the interaction between the firms as a multi-mode differential game, also labeled as piece-wise deterministic game in the literature (see e.g. Dockner et al. (2000) or Dawid et al. (2013)). The initial mode $m_{1}$ denotes the time period before the new product is introduced. The mode $m_{2}$ corresponds to the phase where firm 1 has innovated (and firm 2 therefore will stick to the old product forever) while mode $m_{3}$ refers to the analogous case with firm 2 as the innovator. The mode process $m(t)$ is a Markov process on the set of modes $M:=\left\{m_{1}, m_{2}, m_{3}\right\}$ in continuous time with $m(0)=m_{1}$. The transition rate from $m_{1}$ to $m_{2}$ is given by $h\left(I_{1 r}\right)$, that from $m_{1}$ to $m_{3}$ by $h\left(I_{2 r}\right)$ and all other transition rates are zero. Furthermore, at each transition from $m_{1}$ to $m_{2}$ (or $\left.m_{3}\right)$, the innovator has instantaneous costs of $C_{o n}\left(K_{f, o n}\right)$.

Both firms maximize their expected discounted payoff stream and hence their objective is given by

$$
J_{f}=\mathbb{E}\left\{\int_{0}^{\infty} e^{-r t}\left[p_{o} K_{f o}+p_{n} K_{f n}-C_{o}\left(I_{f o}\right)-C_{n}\left(I_{f n}\right)-C_{r}\left(I_{f r}\right)\right] d t-e^{-r \tau_{f}} C_{o n}\left(K_{f, o n}\right)\right\},
$$

where $\tau_{f}$ denotes the innovation time of firm $f$, which might be infinite if the other firm innovates first, and the expectation is taken with respect to the realization of the transition (time) between the modes of the game.

\section{Markov Perfect Equilibria of the Game}

We consider stationary Markov Perfect Equilibria of the game. A stationary Markovian strategy of firm $f \in 1,2$ is given by a quadruple $\left(\phi_{f o}, \phi_{f r}, \phi_{f n}, K_{f, o n}^{*}\right)$, where the feedback strategies $\phi_{f o}$ and $\phi_{f n}$ describe the optimal dynamic investment to accumulate production capacity for the old and the new product, respectively, and $\phi_{f r}$ denotes the optimal dynamic investment rate in R\&D. For $\phi_{f o}, \phi_{f r}$ and $\phi_{f n}$ it holds that they are a function of the states and the current mode of the game. So, we have that each of these feedback strategies has the form $\phi_{f i}:\left[0, \alpha_{o}\right]^{2} \times\left[0, \alpha_{n}\right]^{2} \times M \rightarrow \mathbb{R}$ for $i \in\{o, n\}$, and $\phi_{f r}:\left[0, \alpha_{o}\right]^{2} \times\left[0, \alpha_{n}\right]^{2} \times M \rightarrow \mathbb{R}_{0}^{+}$. From the definitions of the modes in the model section it follows that $\phi_{f n}=0$ in mode $m_{1}$ since no investment in production capacity of the new product is possible before the product innovation has been accomplished. For the non-innovator, the same holds in mode $m_{2}$ or $m_{3}$. Furthermore, we have $\phi_{f r}=0$ in modes $m_{2}, m_{3}$ because the innovator has already innovated and for the non-innovator it is either impossible to innovate as second due to technological reasons, or useless to innovate since the innovator has patented its innovation. The firm's feedback strategy is completed by the capital transfer function $K_{f, o n}^{*}:\left[0, \alpha_{o}\right]^{2} \rightarrow \mathbb{R}_{+}$determining, as a function of both firms' capacities on the old market, how much capacity the firm, in case it is the innovator, transfers from the old to the new product.

In what follows we present the game in a backward fashion. Section 3.1 deals with modes $m_{2}, m_{3}$, which arise after the innovation of the innovator took place. Section 3.2 treats the problem the innovator faces in determining how much of its production capacity to transfer from the production process of the old product to the new product at the 
time the product innovation process has been completed. Finally, Section 3.3 is about the initial mode $m_{1}$, where the firms are active producers on the old product market and at the same time compete to be the innovator of the new product.

\subsection{Modes after innovation}

The game in modes $m_{2}, m_{3}$ is linear-quadratic and corresponds directly to the game analyzed in Dawid et al. (2010). Proposition 1 in that paper characterizes the linear feedback strategies of an MPE of this game and shows that it has a pair of value functions for the two players of the form (assuming that firm 1 is the innovator)

$$
\begin{aligned}
V_{f}^{m_{2}}\left(K_{1 o}, K_{2 o}, K_{1 n}\right) & =C_{f}+D_{f} K_{1 o}+E_{f} K_{1 o}^{2}+F_{f} K_{2 o}+G_{f} K_{2 o}^{2}+H_{f} K_{1 n}+J_{f} K_{1 n}^{2} \\
& +L_{f} K_{1 o} K_{2 o}+M_{f} K_{1 o} K_{1 n}+N_{f} K_{1 n} K_{2 o}, \quad f=1,2 .
\end{aligned}
$$

Inserting these forms of the value functions and the corresponding feedback functions into the Hamilton-Jacobi-Bellman (HJB) equations for both players and applying the standard procedure of comparing coefficients of all terms up to second order of the state variables on both sides of the HJB yields a system of 20 algebraic equations for the 20 unknown coefficients in the value functions. In combination with the requirement that the state dynamics should have a stable steady state under the equilibrium feedback functions (which follows from the firm's transversality conditions) this system of equations yields a unique pair of equilibrium value functions for the two firms for all parametrizations considered in this paper. ${ }^{1}$

\subsection{Transfer of Capacity}

At the (stochastic) time $\tau$, at which the new product is introduced the innovator (again, we assume this is firm 1) solves the following problem to determine the amount of rollover capacity:

$$
\max _{0 \leq K_{1, o n} \leq K_{1 o}(\tau)}\left[V_{1}^{m 2}\left(K_{1 o}(\tau)-K_{1, o n}, K_{2 o}(\tau), \kappa K_{1, o n}\right)-c_{o n} K_{1, o n}\right] .
$$

Using (3), the solution to this problem can be easily determined. Inserting expression (3) gives

$$
\begin{aligned}
& \max _{0 \leq K_{1, o n} \leq K_{1 o}(\tau)}\left[C_{f}+D_{f}\left(K_{1 o}(\tau)-K_{1, o n}\right)+E_{f}\left(K_{1 o}(\tau)-K_{1, o n}\right)^{2}+F_{f} K_{2 o}(\tau)+G_{f} K_{2 o}^{2}(\tau)\right. \\
& +H_{f} \kappa K_{1, o n}+J_{f} \kappa^{2} K_{1, o n}^{2}+L_{f}\left(K_{1 o}(\tau)-K_{1, o n}\right) K_{2 o}(\tau)+M_{f}\left(K_{1 o}(\tau)-K_{1, o n}\right) \kappa K_{1, o n} \\
& \left.+N_{f} \kappa K_{1, o n} K_{2 o}(\tau)-c_{o n} K_{1, o n}\right] .
\end{aligned}
$$

An optimal $K_{1, \text { on }} \in\left(0, K_{1 o}(\tau)\right)$ thus has to satisfy

$$
\begin{aligned}
& -D_{f}-2 E_{f}\left(K_{1 o}(\tau)-K_{1, o n}\right)+H_{f} \kappa+2 J_{f} \kappa^{2} K_{1, o n}-L_{f} K_{2 o}(\tau)+\kappa M_{f}\left(K_{1 o}(\tau)-2 K_{1, o n}\right) \\
& +N_{f} \kappa K_{2 o}(\tau)-c_{o n}=0,
\end{aligned}
$$

from which we obtain that

$$
K_{1, o n}^{*}=\max \left[0, \min \left[K_{1 o}(\tau), \frac{\left(2 E_{f}-\kappa M_{f}\right) K_{1 o}(\tau)+\left(L_{f}-\kappa N_{f}\right) K_{2 o}(\tau)+D_{f}-\kappa H_{f}+c_{o n}}{2\left(\kappa^{2} J_{f}-\kappa M_{f}+E_{f}\right)}\right]\right] .
$$

\footnotetext{
${ }^{1}$ This does not imply that the MPE in modes $m_{2}$ and $m_{3}$ are necessarily unique, since our method only considers MPE with linear feedback function. In general one should expect that also MPE with non-linear strategies exist.
} 


\subsection{Innovation Race}

Initially both firms are active producers of the established product and try to become the innovator by pursuing their R\&D project. We are in mode $m_{1}$ of the game, the HJB equations of both firms are symmetric, and for firm 1 it is given by

$$
\begin{aligned}
r V_{1}^{m_{1}}\left(K_{1 o}, K_{2 o}\right) & =\max _{I_{1 o}, I_{1 r}}\left[\left(\alpha_{o}-\left(K_{1 o}+K_{2 o}\right)\right) K_{1 o}-\frac{c_{o}}{2} I_{1 o}^{2}-\frac{c_{r}}{2} I_{1 r}^{2}\right. \\
& +\frac{\partial V_{1}^{m_{1}}}{\partial K_{1 o}}\left(I_{1 o}-\delta_{o} K_{1 o}\right)+\frac{\partial V_{1}^{m_{1}}}{\partial K_{2 o}}\left(\phi_{2 o}-\delta_{o} K_{2 o}\right) \\
& +\gamma I_{1 r}\left(V_{1}^{m_{2}}\left(K_{1 o}-K_{1, o n}^{*}\left(K_{1 o}, K_{2 o}\right), K_{2 o}, \kappa K_{1, o n}^{*}\left(K_{1 o}, K_{2 o}\right)\right)-V_{1}^{m_{1}}\left(K_{1 o}, K_{2 o}\right)\right) \\
& \left.+\gamma \phi_{2 r}\left(V_{1}^{m_{3}}\left(K_{1 o}, K_{2 o}-K_{2, o n}^{*}\left(K_{1 o}, K_{2 o}\right), \kappa K_{2, o n}^{*}\left(K_{1 o}, K_{2 o}\right)\right)-V_{1}^{m_{1}}\left(K_{1 o}, K_{2 o}\right)\right)\right] .
\end{aligned}
$$

The first term on the right-hand side stands for the revenue obtained from selling the established product. The second and the third term are the investment costs of the capacity investment and the R\&D investment, respectively. On the second line we depict the effects of the changes in the capital stocks of firm 1 and firm 2 on the value of firm 1. The third line stands for the probability of changing the mode from $m_{1}$ to $m_{2}$ times the corresponding value change, which relates to firm 1 being the innovator. The last line is analogous, but then with firm 2 being the innovator with mode change from $m_{1}$ to $m_{3}$.

Maximization of the right hand side of this HJB equation yields the following representation of the equilibrium feedback functions for firm 1 in mode $m_{1}$ (analogous for firm 2):

$\phi_{1 o}\left(K_{1 o}, K_{2 o}, m_{1}\right)=\frac{1}{c_{o}} \frac{\partial V_{1}^{m_{1}}\left(K_{1 o}, K_{2 o}\right)}{\partial K_{1 o}}$
$\phi_{1 r}\left(K_{1 o}, K_{2 o}, m_{1}\right)=\frac{\gamma}{c_{r}}\left(V_{1}^{m_{2}}\left(K_{1 o}-K_{1, o n}^{*}\left(K_{1 o}, K_{2 o}\right), K_{2 o}, \kappa K_{1, o n}^{*}\left(K_{1 o}, K_{2 o}\right)\right)-V_{1}^{m_{1}}\left(K_{1 o}, K_{2 o}\right)\right)$.

The interpretation of these terms is straight forward. While investment in old market capacity is proportional to the marginal value of an additional unit of capacity, the R\&D investment is driven by the firm's gain from innovation, which already takes into account the optimal capacity transfer in case the firm innovates first.

Substituting these expressions into (4), yields a partial differential equation, which is not linear-quadratic. Hence, closed form representations of the value and feedback functions are not available in this mode. To determine value and feedback functions which (approximately) solve the HJB equation, we rely on a numerical method. In particular, we use a collocation approach employing Chebychev polynomials on the 2-dimensional state space in order to find value and feedback functions corresponding to a MPE of the game in this mode. For details of our numerical approach we refer to Dawid et al. (2017a).

\section{Results}

Our analysis of the effect of a change in the capacity transferability parameter $\kappa$ is based on the following benchmark parameter setting

$$
\alpha_{o}=1, \alpha_{n}=1.25, \eta=0.5, \delta_{o}=\delta_{n}=0.2, c_{o}=c_{n}=10, c_{r}=1, \gamma=0.3, r=0.05 .
$$

Whereas these values have not been calibrated based on a particular industry, we have checked the robustness of our qualitative insights with respect to variations in these parameters. 


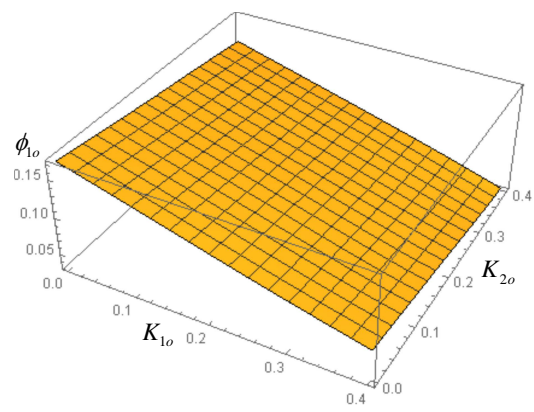

(a)

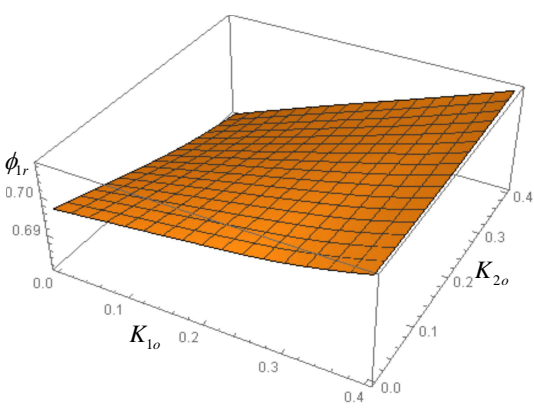

(b)

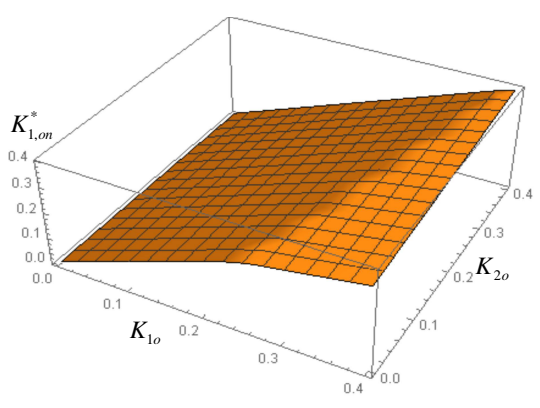

(c)

Figure 1: Equilibrium strategies for (a) investment in production capacity, and (b) investment in $\mathrm{R} \& \mathrm{D}$, in mode $m_{1}$ and (c) transferred capacity to the new product for $\kappa=1$.

We first consider the scenario where the firms can fully transfer capacity from the production process of the established product to the production process of the new product. This occurs in the model when $\kappa=1$. Figure 1 shows the effects of the capacity sizes in the old product market on the different control variables of the firm in mode $m_{1}$. Noting that the steady states are given by $K_{1 o}=K_{2 o}=0.31$, it can be concluded that the most relevant capacity sizes are depicted. In Figure 1a we see that investments in capacity of the old product decreases in the capacity size of the firm itself and of its competitor. This is because the output price of the old product decreases in both these capacities, making these investments less profitable. Most remarkable in Figure 1 is the result in Figure 1b concerning the effect of the capacity of the old product on R\&D investment. Where in Dawid et al. (2017b), in a setting without capacity transfer, this relationship is negative due to cannibalization and size effects, here it turns out to be positive. This is due to the new model feature studied in this paper, namely the transferability of capacity from the old to the new product. Then, if the capacity size on the old market is large, this enables the firm to get a head start in the innovative product market by transferring a lot of this capacity to the production process of the just innovated product. This raises the profitability of innovating, which leads the firm to increase R\&D investments.

Figure 1c is about the capacity amount to be transferred from the production process of the old product to the one of the new product. In the case that transferring the capacity without any loss to the new product is possible, it is almost always optimal to do so, because the new product has a higher reservation price and competition on the output market is lower because the new product is vertically differentiated from the old one. Only in case of a very high old product capacity, not everything is transferred to the new 


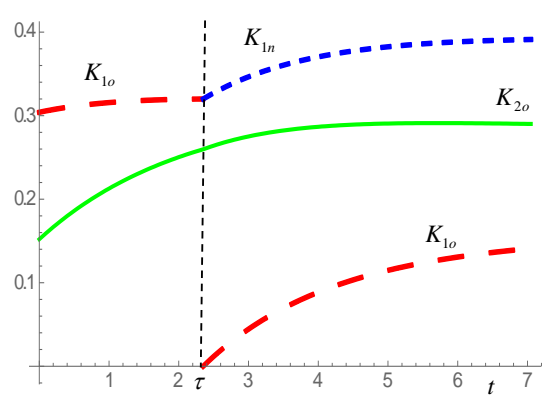

(a)

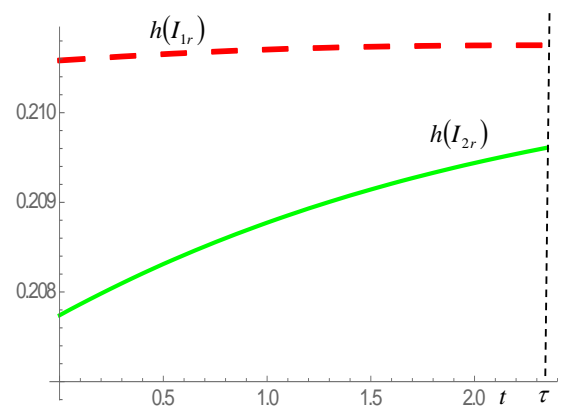

(b)

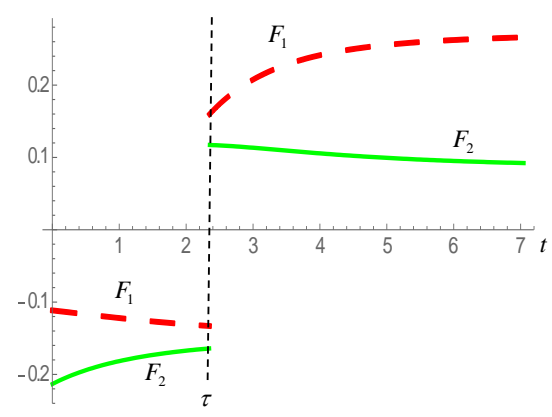

(c)

Figure 2: Dynamics of (a) production capacities, (b) hazard rates, and (c) instantaneous profits for firm 1 (red) and firm 2 (green) for full transfer of capacity, $\kappa=1$.

production process. In particular, if innovation occurs for capacities close to the stable steady state in mode $m_{1}$ of $K_{1 o}=K_{2 o}=0.31$ the innovator transfers the entire capacity to the new product.

In Figure 2 we show the dynamics emerging under these equilibrium strategies. Since we are interested in the comparison of behavior and success of firms of different size on the established market, we consider the dynamics under asymmetric initial capacities on the established market. In particular, in this figure (and all following figures) we assume that the initial capacity of firm 1 is given by the steady state value (under equilibrium investment strategies) of the capital accumulation game without the option to innovate (i.e. the game for $\gamma=0$ ), whereas firm 2 initially has half of this capacity. For the purpose of illustration of the dynamics, we show in the figure a run in which firm 1 innovates before firm 2 can do so and the innovation time $\tau$ is equal to the expected innovation time under the equilibrium strategies.

Figure 2a shows that initially both firms increase capacity. Despite the fact that it starts out from its steady state value for the model without the option to innovate, also firm 1 increases its capacity size. It does so, because it anticipates the innovation breakthrough at which it will transfer all of its production capacity to the production process of the more profitable new product. At time $\tau$, firm 1 introduces the new product to the market and indeed transfers all of its production capacity to the new product. From that moment on, firm 1 builds up capacity for the old product from scratch and also invests to increase the new product capacity size. Firm 2 solely produces the old product and keeps on increasing its capacity all along. Initially, this is because the capacity size at time zero is only half the steady state value. After the innovation breakthrough of firm 1, the product market 


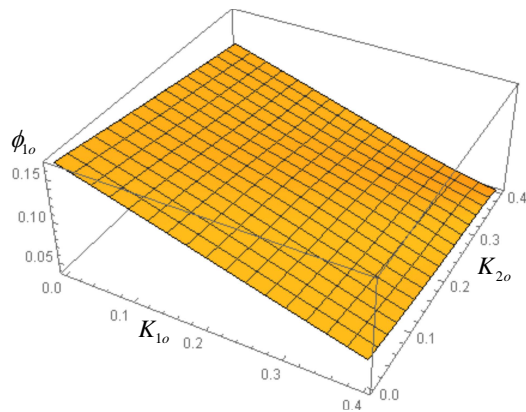

(a)

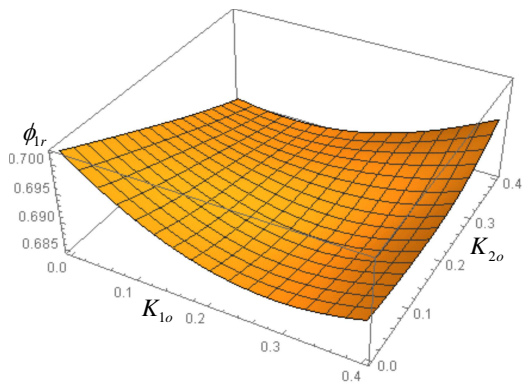

(b)

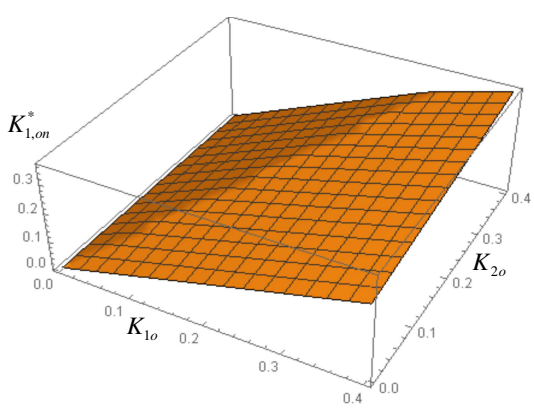

(c)

Figure 3: Equilibrium strategies for (a) investment in production capacity, (b) investment in $\mathrm{R} \& \mathrm{D}(\mathrm{b})$ in mode $m_{1}$ and (c) transferred capacity to the new product for $\kappa=0.8$

becomes heterogeneous. Then firm 1 only sells a small amount of the old product, which enlarges the profitability of firm 2, giving the latter firm an additional incentive to grow. Note that the steady state capacity size of the old product in mode $m_{2}$ is larger for firm 2 than for firm 1. This is because more sales of the old product reduce the output price of the new product, which is why firm 1 keeps the capacity size of the old product at a lower level.

Figure $2 \mathrm{~b}$ confirms that the larger firm 1 has more incentive to innovate, because we see here that firm 1's hazard rate is larger throughout the innovation race time window (mode $\left.m_{1}\right)$. The hazard rate of firm 2 grows significantly over time though. This is because, as we know from Figure 2a, firm 2's productive capacity grows significantly as well. This gives firm 2 the opportunity to transfer more capacity of the old to the new production process, which enlarges the value of the product innovation. Figure 2c shows that the change from a homogeneous to a heterogeneous product market at the time of firm 1's product innovation, turns the loss-making situation in a profitable one for both firms. The initial high investments, inducing losses in mode $m_{1}$ are still optimal because the firms anticipate the potential gains from product innovation and from the future transfer of the production capacity to the production process of the more profitable new product. The reasons why also the non-innovator becomes profitable after $t=\tau$ are twofold. First, the innovator moves its capacities out of the old market, which increases the price on this market and, second, the firm stops investing in product innovation since there is no more chance to introduce the new product.

If the capacity is not fully transferable from the old to the new product $(\kappa<1)$, the feedback strategies and the resulting dynamics change substantially. In Figure 3, 


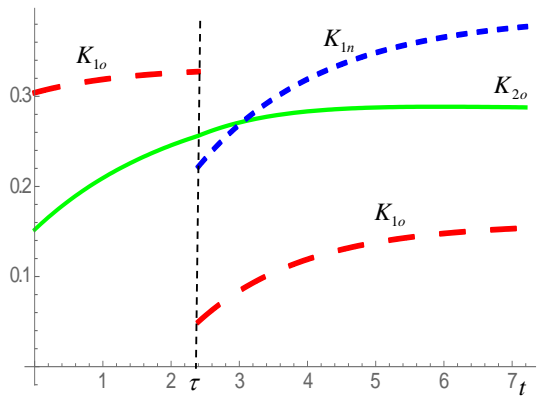

(a)

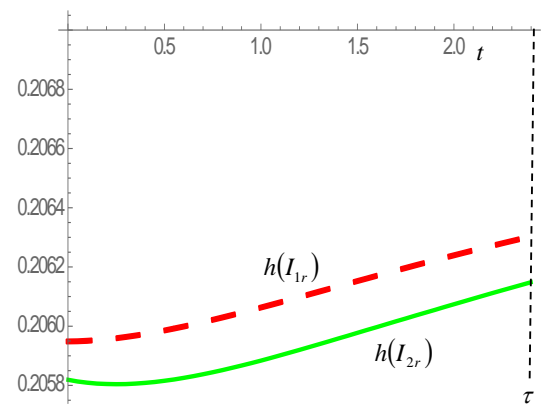

(b)

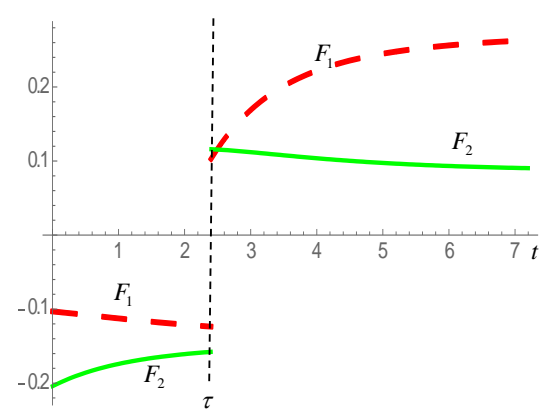

(c)

Figure 4: Dynamics of (a) production capacities, (b) hazard rates, and (c) instantaneous profits for firm 1 (red) and firm 2 (green) and partially transferable capacity, $\kappa=0.8$.

the investment strategies and the amount of transferable capacity is shown for $\kappa=0.8$, corresponding to a case where only a relatively small loss in overall capacity occurs if production equipment is re-used for the production of the new product. Most notably, one can see from panel $(b)$ of the figure that the investment in $R \& D$ is no longer strictly increasing with respect to the firm's own production capacity on the old market, but rather is U-shaped. This reflects the trade-off between two effects, the first effect being the cannibalization effect which highlights that if the capacity of the old product becomes larger, introducing the new product induces a larger reduction of the revenue of the old product. This reduces the incentive to innovate (Dawid et al. (2017b)). The second effect is that a larger old product capacity enlarges the value of the product innovation, because the firm is able to transfer a larger production capacity to the new product. The fact that now there is some leakage in the transfer of the production capacity makes that, unlike in the situation of Figure 1, the second effect not always dominates the first effect. In particular, it holds that the first effect is more dominant for smaller production capacity levels. Considering the optimal capacity transfer policy shown in Figure 3c, it can be clearly seen that the part of the state space in which the innovator transfers its entire capacity to the new product is substantially smaller than in the case of full transferability $(\kappa=1)$. In particular, close to the steady state capacity levels the innovator now leaves some capacity for the production of the old product when entering the new market.

These properties are also reflected in the dynamics shown in Figure 4. Compared to Figure 2 we observe a smaller hazard rate of firm 1 in Figure 4b, since the fact that now not all production capacity is transferable reduces the profitability of innovation. The change in the dynamics of the production capacities on the old market (Figure 4a) also 


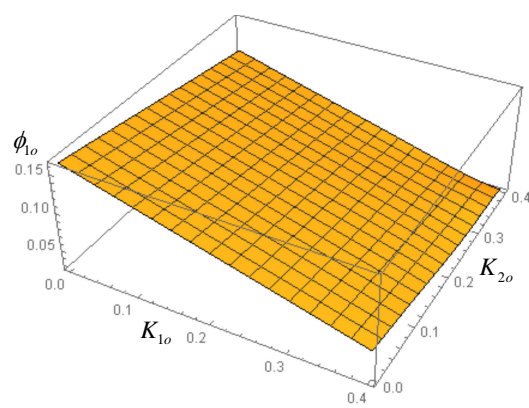

(a)

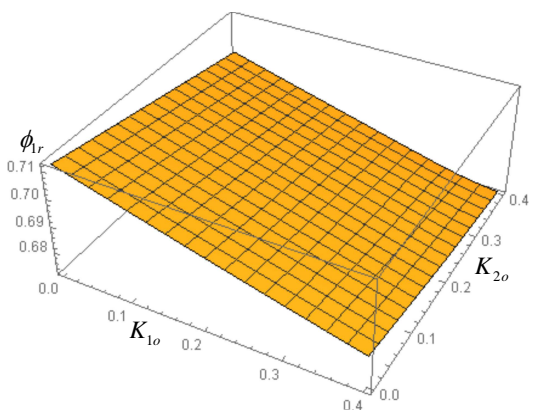

(b)

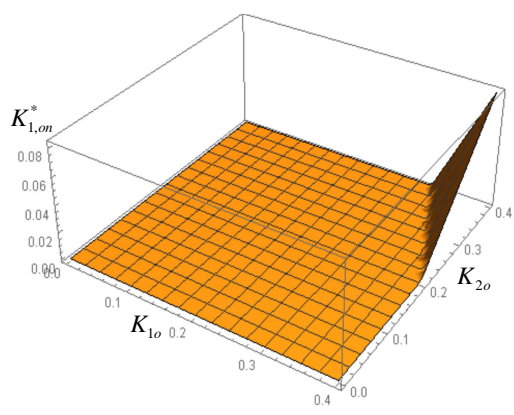

(c)

Figure 5: Equilibrium strategies for (a) investment in production capacity, (b) investment in R\&D (b) in mode $m_{1}$, and (c) transferred capacity to the new product for $\kappa=0.3$

follows directly from our discussion above.

If the loss of capacity upon transfer from the old to the new product is even stronger $(\kappa=0.3)$, the firm essentially stops to use this option, as is illustrated in Figure 5c. Since in a large part of the state space, including the steady state in mode $m_{1}$, it is not optimal for the firm to transfer any capacity, we are in fact back in the situation without the possibility of capacity transfer studied in Dawid et al. (2017b). This implies that R\&D investments are decreasing in its old product capacity size due to the cannibalization effect, which is bigger for larger firms (Figure 5b). Figure 6 confirms this conclusion by showing that the hazard rate of the smaller firm is now above the hazard rate of the larger firm for all $t$. Whereas the hazard rate of the larger firm 1 is substantially lower than in the cases of $\kappa=1$ and $\kappa=0.8$, the hazard rate of the smaller firm 2 at least initially is larger than it is for $\kappa=0.8$. At first sight this might be surprising, since also for the small firm the reduced transferability of capacities reduces the profit from innovating. However, it also has to be taken into account that the profit of firm 2, if firm firm 1 innovates, is smaller under $\kappa=0.3$ than under $\kappa=0.8$ (compare panels (c) in Figures 6 and 4). Overall, winning rather than loosing the innovation rate is more important for the small firm under lower transferability of capacities than for large values of $\kappa$. Finally, the increase of capacities on the old market now make that the hazard rates are decreasing over time.

To study the effect of a variation of $\kappa$ more systematically, in Figure 7 we depict the value function of the two firms, the probability of the larger firm (firm 1) to innovate first, and the expected innovation time as a function of $\kappa$. The latter is in fact equal to the expected value of the minimum of the innovation times of the two firms. All values are based on the same initial conditions we have used throughout the analysis before, 


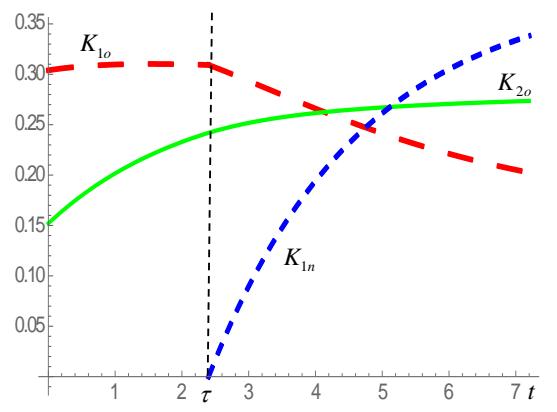

(a)

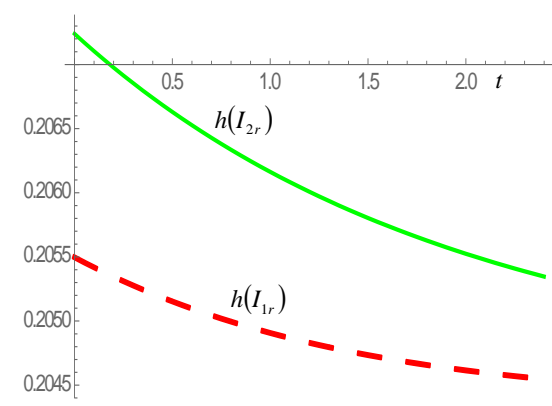

(b)

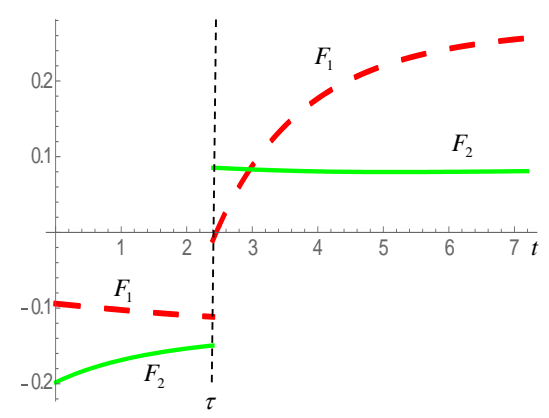

(c)

Figure 6: Dynamics of (a) production capacities, (b) hazard rates, and (c) instantaneous profits for firm 1 (red) and firm 2 (green) and $\kappa=0.3$.

which means that again firm 1 has a larger capacity on the old market than firm 2. For a grid of 11 equally distanced $\kappa$ values in $[0,1]$ the value functions have been calculated via collocation. In order to determine the probability of firm 1 to innovate first and the expected innovation time, we numerically determine the hazard rates of the two firms along the trajectories using the feedback strategies derived from the value functions for the corresponding value of $\kappa$.

Since the firm does not transfer any capacity as long as $\kappa \leq 0.3$, all values are constant for this range in Figure 7. For larger values of $\kappa$ the value of both firms increases with $\kappa$. This reflects that for the innovator transferring production capacity with lower capacity loss always adds value in situations where firms actually use this option of transferring capacity upon product innovation. It also reflects that, as discussed above, the noninnovator is positively affected by a capacity transfer of the innovator as well. Panel (a) of the figure also highlights that a smaller firm profits already from a relatively small level of transferability compared to a larger firm, i.e. the minimal value of $\kappa$ above which the value function in mode $m_{1}$ increases with respect to that parameter is smaller for firm 2 than for firm 1 . The value of the larger firm is higher, because it owns a larger capacity on the old market.

We have seen before that a larger value of $\kappa$ enlarges the effect that, due to the fact that more capacity can be transferred, the value of the product innovation increases with old market capacity size. For $\kappa$ sufficiently large this effect will outweigh the known cannibalization effect that the value of innovation is reduced by a larger old market production capacity because of a higher old product revenue loss when the new product is introduced to the market. This explains why in Figure $7 \mathrm{~b}$ the probability for the larger firm to win 
the patent race is higher than that of smaller firm for $\kappa$ large enough.

One might expect that the incentive to innovate goes up, and thus the expected innovation time goes down, if a capacity transfer from old to new production capacity involves a smaller capacity loss. However, Figure $7 \mathrm{c}$ shows that for an intermediate range of $\kappa$-values the expected time to innovate increases with $\kappa$. The reason for this non-monotonicity is that, as can be seen from our comparison of $\kappa=0.3$ with $\kappa=0.8$ above, in a certain range an increase of $\kappa$ induces an increase of $R \& D$ investment only for the larger firm, whereas the smaller firm, which for these $\kappa$ values is more likely to win the race, actually reduces its R\&D investment. Since the overall innovation time is given by the minimum of the innovation times of the two firms, this results in a non-monotonic effect of a change in $\kappa$ on the innovation time.

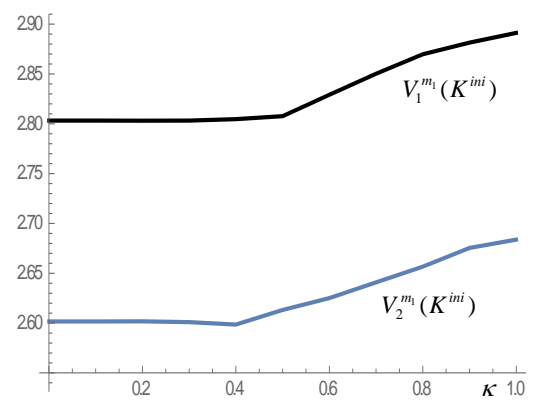

(a)

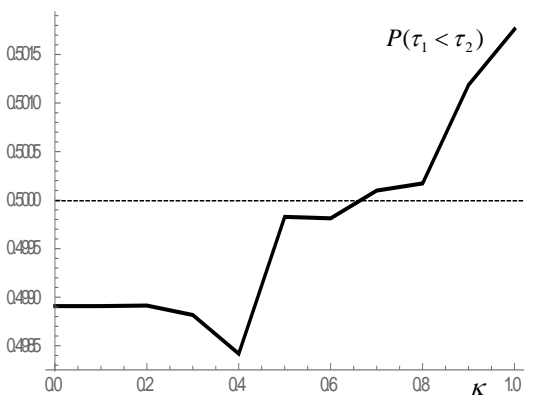

(b)

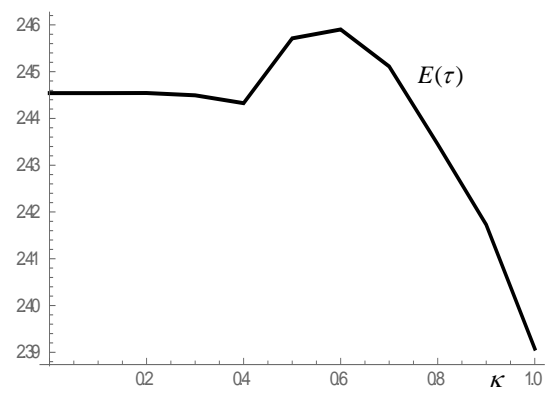

(c)

Figure 7: Value functions of both firms (a), probability of Firm 1 to innovate first (b) and expected innovation time (c) for $\kappa \in[0,1]$.

\section{Conclusions}

The literature contains a series of papers (Dawid et al. (2010), (2013), (2017b)) on product innovation, in which the firm has to build up the production capacity for the new product from scratch. In these papers the firms are active on an established product market, where it is shown how this affects the incentive to innovate. The present paper extends this literature by allowing the firm to rollover (part of) the production capacity from the established production process to the new one. In this sense the paper is also related to Liang et al. (2014), where the firm has the choice between single rollover, i.e. stop producing the established product after the market launch of the new product, or dual 
rollover, meaning that the firm produces both products simultaneously after the new product has been introduced.

The common denominator of the different Dawid et al. papers until now is that the larger firm has less incentive to innovate. The reason is that introducing the new product reduces the output price for the established product, and this effect is more damaging in case of larger production quantities. In other words, the product innovation cannibalizes revenue on the old market, where this effect increases with the firm's capacity size. However, this result is not always observed in reality. For instance, think about the mobile phone market, where conglomerates like Apple and Samsung are very active in introducing new generations of smartphones. The major result of the present paper is that the option to transfer capacity to the production process of the new product in fact could explain why, in spite of the larger cannibalization effect, larger firms can still have a large incentive to innovate. The reason is that, when a firm owns a large production capacity on the established market, it is able to rollover a large capacity to the new product market. This increases revenue associated with the product innovation and thus increases the value of the innovation. We show that this effect outweighs the cannibalization effect when the capacity loss associated with the rollover transfer is limited.

\section{References}

Caulkins J.P., G. Feichtinger, D. Grass, R.F. Hartl and P.M. Kort, 2011, Two state capital accumulation with heterogenous products: Disruptive vs. non-disruptive goods, Journal of Economic Dynamics and Control, 35, 462-478.

Colombo, L. and Labrecciosa, P., 2017, Differential Games in Industrial Organization. In: T. Basar and G. Zaccour (eds) Handbook of Dynamic Game Theory, Springer: Berlin, pp. 779-825.

Dawid H., Keoula M., Kort P.M., 2017a, Numerical Analysis of Markov-Perfect Equilibria with Multiple Stable Steady States: A Duopoly Application with Innovative Firms, Dynamic Games and Applications, 7, 555-577.

Dawid, H., M.Y. Keoula, M. Kopel, and P.M. Kort, 2017b, Dynamic investment strategies and leadership in product innovation, Bielefeld Working Papers in Economics and Management No. 03-2017.

Dawid, H., M. Kopel, and P.M. Kort, 2010, Strategic interaction between an innovating and a non-innovating incumbent, Central European Journal of Operations Research, 18, 453-463.

Dawid, H., M. Kopel, and P.M. Kort, 2013, New product introduction and capacity investment by incumbents: effects of size on strategy, European Journal of Operational Research, 230, 133 - 142.

Dockner, E.J., 1992, A dynamic theory of conjectural variations, The Journal of Industrial Economics 40, 377-395.

Dockner, E.J., G. Feichtinger and A. Mehlmann, 1993, Dynamic R\&D competition with memory, Journal of Evolutionary Economics, 3,145-152.

Dockner, E.J., S. Jorgensen, N.V. Long and G. Sorger, 2000, Differential games in economics and management science. Cambridge University Press, Cambridge.

Dockner, E.J. and G. Mosburger, 2007, Capital accumulation, asset values, and imperfect product market competition, Journal of Difference Equations and Applications 13, 197215. 
Dockner E.J. and F.O.O. Wagener, 2014, Markov-perfect Nash equilibria in models with a single capital stock, Economic Theory 56, 585-625.

Fershtman C. and E. Muller, 1984, Capital accumulation games of infinite duration, Journal of Economic Theory 33, 322-339.

Kort, P.M., S. Jorgensen, and E.J. Dockner, 2006, Venture capital financed investments in intellectual capital, Journal of Economic Dynamics and Control 30, 2339-2361.

Liang, C., C. Çakanyıldırım, and S.P. Sethi, 2014, Presence of strategic customers, Management Science 60, 1033-1056.

Reynolds, S., 1991, Dynamic oligopoly with capacity adjustment costs, Journal of Economic Dynamics and Control 15, 491-514. 